\title{
Postoperative Pneumomediastinum with Bilateral Pneumothorax Following Percutaneous Nephrolithotomy
}

\author{
Deepak Dwivedi, Saurabh Sud, Shalendra Singh'1, Mohit Kumar \\ Department of Anaesthesia and Critical Care, Command Hospital (Southern Command), Armed Forces Medical College, 'Department of Anaesthesia and Critical Care, \\ Armed Forces Medical College, Pune, Maharashtra, India
}

\section{Abstract}

Postoperative pulmonary complications are uncommon following percutaneous nephrolithotomy (PCNL). However, evidence has shown the occurrence of pneumothorax and pneumomediastinum following PCNL. Such life-threatening complications can prove catastrophic if not diagnosed and intervened immediately. Perioperative point-of-care lung ultrasound can play a pivotal role in immediate diagnosis of the pneumothorax and resultant timely intervention limits the morbidity in the immediate postoperative period.

Keywords: Percutaneous nephrolithotomy, pneumomediastinum, pneumothorax, subcutaneous emphysema

\section{INTRODUCTION}

The incidence of complications associated with percutaneous nephrolithotomy (PCNL) varies between 5\% and 10\%. They include renal pelvis perforation, fever, postoperative pulmonary complications (PPCs), and hemorrhage requiring transfusion being the most common. ${ }^{[1]}$ This report highlights the development of bilateral pneumothorax, pneumomediastinum, and surgical emphysema following PCNL surgery. The incidence of pneumothorax is around $87 \%$ in the patients who had $8 \%$ of PPC following PCNL. ${ }^{[2]}$ Other causes of pneumothorax and pneumomediastinum are trauma, gastrointestinal tract endoscopic procedures, esophageal or alveolar rupture, bowel perforation, and retroperitoneal space air leak into the mediastinum. ${ }^{[3]}$

\section{Case Report}

A 35-year-old female weighing $60 \mathrm{~kg}$ with no comorbidities, a case of left nephrolithiasis, was planned for left PCNL. Preoperative investigations were within the normal limits. Written informed consent, fasting status, was confirmed. Standard monitoring ensued. General anesthesia (GA) was administered with injection propofol $(120 \mathrm{mg})$, injection fentanyl $(100 \mu \mathrm{g})$, and injection atracurium $(30 \mathrm{mg}$ ) intravenously. The patient was operated in the prone position. GA was maintained with sevoflurane, oxygen, and nitrous oxide to achieve a minimum alveolar concentration of $1 \%-1.2 \%$.

\begin{tabular}{|l|l|}
\hline \multicolumn{2}{|c|}{ Access this article online } \\
\hline Quick Response Code: & Website: \\
& www.ijrconline.org \\
\cline { 2 - 2 } & \\
\end{tabular}

The patient was ventilated with tidal volume of $6 \mathrm{ml} / \mathrm{kg}$, and the peak airway pressures were maintained between 14 and $18 \mathrm{~cm} \mathrm{H_{2 }} \mathrm{O}$. Hemodynamics was maintained throughout the surgery, and the intraoperative period was uneventful. The patient was extubated in the supine position. However, despite complete reversal of neuromuscular blockade, the patient's oxygen saturation $\left(\mathrm{SpO}_{2}\right)$ was $84 \%$ on room air. During oxygen supplementation with facemask, fingers felt crepitus in the submandibular region, and on further inspection, subcutaneous emphysema was noticed extending from the neck to the bilateral chest and subcostal area. On auscultation of the chest, there was decreased bilateral air entry. Lung ultrasound showed bilateral absence of lung sliding and seashore sign. Immediately, bilateral chest tubes were inserted in the fifth intercostal space in the mid-axillary line. The patient's $\mathrm{SpO}_{2}$ improved from $88 \%$ to $96 \%$ on room air. The patient was shifted to the intensive care unit (ICU) for further monitoring. X-ray chest in the ICU showed the presence of pneumomediastinum with the resolution of pneumothorax [Figure 1]. The patient

Address for correspondence: Dr. Saurabh Sud, Department of Anaesthesia and Critical Care, Command Hospital (Southern Command), Armed Forces Medical College, Pune - 411 040, Maharashtra, India. E-mail: saurabhsood1975@gmail.com

This is an open access journal, and articles are distributed under the terms of the Creative Commons Attribution-NonCommercial-ShareAlike 4.0 License, which allows others to remix, tweak, and build upon the work non-commercially, as long as appropriate credit is given and the new creations are licensed under the identical terms. For reprints contact: reprints@medknow.com

How to cite this article: Dwivedi D, Sud S, Singh S, Kumar M. Postoperative pneumomediastinum with bilateral pneumothorax following percutaneous nephrolithotomy. Indian J Respir Care 2020;9:113-5.

Received: $11-07-2019$ Accepted: 01-10-2019

Revised: 26-09-2019 Published: 08-01-2020 
Dwivedi, et al.: Postoperative pulmonary complications after PCNL

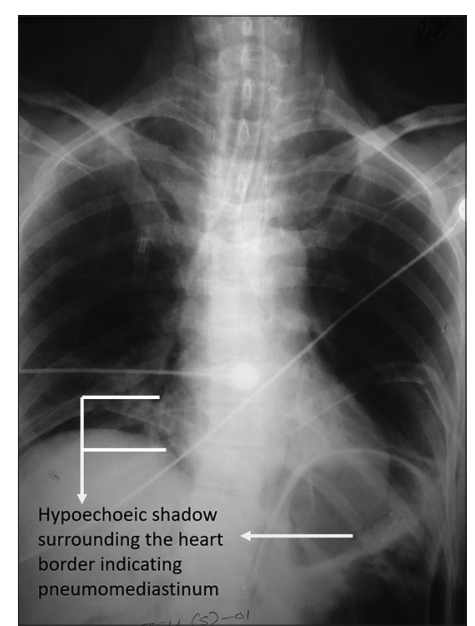

Figure 1: X-ray chest anteroposterior view shows hypoechoic shadow along the heart border indicating pneumomediastinum

was managed conservatively with bed rest, oxygen through nasal cannula, and analgesics. Repeat check X-ray after 2 days showed the resolution of the pneumomediastinum, and the patient was discharged to home after 5 days.

\section{Discussion}

Pnuemomediastinum can be classified as spontaneous which is associated with tobacco and cocaine use, secondary due to the iatrogenic causes which include chest and abdominal surgeries, following airway and esophageal endoscopies, oral intubation, and pleural cavity instrumentations. Other causes of secondary pnuemomediastinum include blunt or penetrating injuries of the chest and abdomen, pulmonary metastasis as well as asthma and chronic obstructive pulmonary disease. ${ }^{[4]}$

Wang et al. have described bilateral pneumothorax, pneumomediastinum, and surgical emphysema in a patient with a history of smoking and bilateral bullae in the lower lobes of the lung. A bout of cough before extubation triggered pneumothorax in their case requiring tube thoracostomy. ${ }^{[5]}$ Similar episode of cough leading to pneumothorax was observed by Gianesello et al. in the patient with lung metastasis. A cough reflex can generate intra-alveolar pressure up to $400 \mathrm{~cm}$ of $\mathrm{H}_{2} \mathrm{O}$ causing rupture of the blebs in the lung, resulting in pneumothorax. ${ }^{[6]}$ GA-related pneumothorax can be suspected during routine ventilation in a patient with known pulmonary pathology, wherein sticky one-way valves or kink in the circuits cause retrograde transmission of high airway pressure to the alveoli. Endotracheal intubation was atraumatic, and occlusion of the tubing of the breathing system or of the scavenging system was ruled out in our case. ${ }^{[7]}$ Suspicion arises intraoperatively when the peak airway pressure is above $50 \mathrm{~cm}$ of $\mathrm{H}_{2} \mathrm{O}$, positive end-expiratory pressure is $>18 \mathrm{cmH}_{2} \mathrm{O}$, or there is decreased compliance and increased resistance to ventilation. However, none of the findings were present intraoperatively in our case, thereby ruling out anesthesia or patient-related factors. ${ }^{[6,8]}$
The common mechanism for developing pneumomediastinum is an alveolar rupture, retroperitoneal air collection, and anatomical predisposition. Alveolar rupture following increase in alveolar pressure is the most common cause of pneumomediastinum leading to the transgression of air along the perivascular and peribronchial sheaths into the mediastinum. ${ }^{[3]}$ Wang et al. reported a case of pneumomediastinum caused by the collection of retroperitoneal air, produced by bacteria in a case of emphysematous pyelonephritis. ${ }^{[9]}$ Abreu et al. had observed increased incidence of pneumomediastinum in retroperitoneal procedures as compared to transperitoneal procedures performed during urological laparoscopic surgeries. ${ }^{[10]}$ Anatomical absence of subdiaphragmatic peritoneum and communication of retroperitoneal space with the mediastinum through tracheal and esophageal opening in the diaphragm leads to pneumomediastinum due to migration of air from the retroperitoneal space to the mediastinum. ${ }^{[3]}$

The most probable cause of pneumomediastinum in our case was procedure related where the air was erroneously introduced via irrigating system employed during PCNL into the kidney's collecting system, as also being described by Chang et al.$^{[3]}$ The accumulated air in the retroperitoneal space could have migrated to the mediastinum along the esophageal or aortic opening, causing pneumomediastinum. The air further penetrated through the mediastinal fascia, overlying pleura into the pleural space, and fascial layers of the neck leading to pneumothorax and subcutaneous emphysema, respectively. Palnizky et al. observed increased incidence of pneumothorax in young patients undergoing left-sided PCNL, probably due to the procedure per se and the proximity of the lung to the left kidney. ${ }^{[2]}$

\section{Conclusion}

PPCs related to PCNL are potential life-threatening situations, but vigilance is of paramount importance in identifying the etiology and timely intervention helps in limiting such events. Utmost care needs to be taken whenever the irrigation system is used to prevent any ingress of air into the tubing of the irrigation system to limit any inadvertent air introduction into the retroperitoneal space. Point-of-care lung ultrasound used by an anesthesiologist has once again reiterated its pivotal role in the early diagnosis which facilitated early intervention by the surgeon. This prevented the morbidity and mortality related to the development of the pneumothorax in the immediate postoperative period.

\section{Declaration of patient consent}

The authors certify that they have obtained all appropriate patient consent forms. In the form, the patient has given her consent for her images and other clinical information to be reported in the journal. The patient understands that her name and initials will not be published and due efforts will be made to conceal her identity but anonymity cannot be guaranteed.

\section{Financial support and sponsorship} Nil. 
Dwivedi, et al:: Postoperative pulmonary complications after PCNL

\section{Conflicts of interest}

There are no conflicts of interest.

\section{RefERENCES}

1. de la Rosette J, Assimos D, Desai M, Gutierrez J, Lingeman J, Scarpa R, et al. The clinical research office of the endourological society percutaneous nephrolithotomy global study: Indications, complications, and outcomes in 5803 patients. J Endourol 2011;25:11-7.

2. Palnizky G, Halachmi S, Barak M. Pulmonary complications following percutaneous nephrolithotomy: A prospective study. Curr Urol 2013;7:113-6.

3. Chang $\mathrm{CH}$, Jou $\mathrm{YC}, \mathrm{Wu} \mathrm{CH}$, Hsieh $\mathrm{CW}$. Pneumomediastinum: An unusual complication after percutaneous nephrolithotomy. Ci Ji Yi Xue Za Zhi 2017;29:118-20.

4. Kouritas VK, Papagiannopoulos K, Lazaridis G, Baka S, Mpoukovinas I, Karavasilis V, et al. Pneumomediastinum. J Thorac Dis 2015;7:S44-9.

5. Wang Y, Shi B, Li Y, Wang N. Spontaneous bilateral pneumothorax, pneumomediastinum, and subcutaneous emphysema following intracranial aneurysm clipping under general anesthesia. Anesth Essays Res 2019;13:184-7.

6. Gianesello L, Boccaccini A, Rostagno C. Bilateral pneumothorax after general anesthesia in patient with pleomorphic sarcoma of soft tissue. SAGE Open Med Case Rep 2019;7:1-3.

7. Murthy TV, Kale R, Biswas M, Gogna RL, Ramesh GS. Unusual incidence of pneumothorax following general anaesthesia. Indian J Anaesth 2006;50:483-5.

8. Lee SJ, Lee DJ, Kim MC, Im UJ. Pneumothorax in a post-anesthetic care unit after right thyroidectomy with left neck dissection -A case report. Korean J Anesthesiol 2010;59:429-32.

9. Wang YC, Wang JM, Chow YC, Chiu AW, Yang S. Pneumomediastinum and subcutaneous emphysema as the manifestation of emphysematous pyelonephritis. Int J Urol 2004;11:909-11.

10. Abreu SC, Sharp DS, Ramani AP, Steinberg AP, Ng CS, Desai MM, et al. Thoracic complications during urological laparoscopy. J Urol 2004; 171:1451-5. 